\title{
The Predictors of Cardio-renal Syndrome among Patients with COVID-19 Infection
}

\author{
Aber Halim Baki ${ }^{1}$, Hazem Mansour ${ }^{2}$, Ahmed Tareq El Khouly ${ }^{3}$, \\ Osama Mohamad Farrag ${ }^{3}$ \\ ${ }^{1}$ Department of Internal Medicine and Nephrology,Ain Shams University Hospitals, Cairo,Egypt. \\ ${ }^{2}$ Department of Cardiology,Ain Shams University Hospitals, Cairo, Egypt. \\ ${ }^{3}$ Department of ICU,Ain Shams University Hospitals, Cairo,Egypt.
}

Corresponding Author Aber Halim Baki

Mobile:

$+201224037210$

E mail:

aberhalim@hotmail. com

Key words:

Cardio-renal

Syndrome

(CRS),

Covid-19, cytokine

storm, Predictors
Background and study aim: : Several reports showed that some Covid-19 patients tend to have serious and fatal complications related to the kidney and heart. Rationale and mechanisms inducing this pathogenesis is unclear, but it's more common to happen in patients with hemodynamic instability and refractory severe hypotension related to cytokine storm. It represents an irreversible stage of a sepsis-like illness that induces simultaneous damage to various organs as the myocardium and renal tubules alike the cardio-renal syndrome. The predictors for this injurious effect of COVID-19 on both myocardium and renal tissues might be related to the co-morbidities, late presentation and other factors which need further evaluation. The aim of this article is to study the predictors of cardio-renal syndrome in COVID-19 patients

Patients and Methods: Our study is a prospective observational study conducted upon confirmed 160 COVID19 ICU patients admitted from 15th
March till 20th May 2020. All patients were subjected to clinical assessment, full laboratory evaluation including PCR for COVID-19 from nasopharyngeal swab and full radiological evaluation..

Results: As regards the predictors for cardio-renal syndrome [15-17]; Age showed high statistically significance $(\mathrm{P}$ $<0.0004)$. Furthermore, serum creatinine and serum $\mathrm{K}$ were statistically significant in patients with cardio-renal affection $(\mathrm{P}=$ $0.015,0.021)$ whereas GFR, D-dimer, need for mechanical ventilation and vasopressors were highly statistically significant with cardio-renal affected patients $(\mathrm{P}<0.001)$.

Conclusion: Cardio-renal syndrome was common in COVID-19 ICU patients. Hypokalemia, lower GFR on admission, mechanical ventilation, vasopressors, age and D-dimer were significant independent predictors for CRS. Moreover,CRS during hospitalization was associated with an increased risk of in-hospital death.

\section{INTRODUCTION}

COVID-19 infection has exhibited a heterogeneous clinical course, ranging from asymptomatic carrier scenario to a lethal one with multi-organ failure with a wide variation of case fatality rates ranging from 0.7 to $67 \%[\mathbf{2 , 3}, \mathbf{4}]$. Other organs than the respiratory tract such as the heart, the kidney, are also affected with a negative prognostic impact [5]. Although there are some ongoing studies investigating cardiovascular and kidney affection in patients with COVID-19, there are still several unanswered inquiries, most importantly a risk stratification system and predictors that permit proper identification of high-risk patients [6].

So, our study aims to estimate the percentage and predictors of newly developed CRS as a sequela in COVID-19 ICU patients. 


\section{METHODS}

In this single group cross sectional comparative study conducted upon a total of 160 COVID19 patients admitted in the ICU at Ain Shams Specialized Hospital in Cairo from the 15th of March to the 20th of May 2020.

All patients were subjected to complete history, physical examination laboratory assessment which included renal function tests, liver function tests, CBC, troponin I, LDH, Cpk total and $\mathrm{MB}$, D-Dimer, ferritin, CRP, creatinine Clearance by MDRD formula, urine analysis; Radiological evaluation using Echocardiography, CXR, CT chest High resolution and pelvi-abdominal US.

All patients (age range 26-81 years) who were enrolled in this study were diagnosed COVID-19 positive according to the following diagnostic criteria:

(i)Fever or respiratory symptoms and (ii)l eukopenia or lymphopenia; and (iii) The computerized tomography scan showing radiographic abnormalities suggestive of covid19 lung affection (CORADS-3 or above). Those with $\geq 2$ clinical diagnosis criteria and having a positive polymerase chain reaction assay(PCR) for a nasopharyngeal swab were diagnosed COVID-19-positive.

\section{Exclusion Criteria:}

Patients with a history of maintenance dialysis, renal transplantation, left ventricular (LV) dysfunction (LV Ejection fraction $<55 \%$ ) and significant valvular disease were excluded from the study.

The demographic characteristics included age and sex ,smoking \& comorbidity like COPD, DM, HTN, IHD, clinical symptoms, laboratory data, and medications including intravenous (IV) vasopressors if needed, need of mechanical ventilation(MV) and duration of MV were gathered from our medical records.

\section{Definitions:}

Acute Kidney Injury (AKI) was defined as an increase in serum creatinine by $\geq 0.3 \mathrm{mg} / \mathrm{dl}$ within 48 hours or a $\geq 50 \%$ increase in serum creatinine from baseline within 7 days according to the KDIGO criteria [7].

Cardiac injury was defined as rise of blood levels of cardiac troponin above the 99th-percentile upper reference limit (Hs-Troponin I reference level $=2-100 \mathrm{ng} / \mathrm{l}$ ), with or without associated ECG or Echocardiographic findings and after exclusion of non-cardiac causes of troponin elevation.

Cardio-renal syndromes (CRS) are 5 types of heart and kidney disorders in which acute or long-term malfunction in one organ might prompt acute or long-term dysfunction of the other one [9].

Our study evaluated covid 19 patients presented by CRS types $1,3,5$ in which simultaneous injury or one preceding the other for both myocardium and kidney might be induced by cytokine storm. Type I: Acute cardiorenal syndrome is acute kidney injury (AKI) which is hemodynamically mediated, secondary to acute cardiac decompensation. Type III: Acute renocardiac syndrome is acute worsening of renal function leading to heart failure as in acute glomerulonephritis which can cause flash pulmonary edema. Type V: Secondary cardiorenal syndrome in which same pathological factor causes injury to both the heart and the kidneys as in diabetes mellitus and sepsis [9].

\section{Statistical Methods:}

\section{Sample size calculation}

The required sample size has been calculated using the formula described by Naing et al. (2006) for estimation of proportions from a single population [8].

Assuming an incidence rate of CRS of around $7 \%$ in COVID-19 patients as observed from the incidence recorded at our unit, we calculated that a sample size of 157 patients would estimate this incidence rate with a precision of $\pm 4 \%$, i.e., with $95 \%$ confidence limits ranging from $3 \%$ to $11 \%$. For reasons of convenience, we recruited 160 patients.

Data were analyzed using MedCalc $@$ version 18.2.1 (MedCalc $\odot$ Software bvba, Ostend, Belgium).

Non-normally distributed numerical variables were presented as median and interquartile range and between-group differences were compared using the Mann-Whitney test. Categorical variables were presented as number and percentage and differences were compared using Fisher's exact test as appropriate.

Variables associated with occurrence of Cardiorenal syndrome (CRS) on bi-variable analysis

Baki et al., Afro-Egypt J Infect Endem Dis 2021;11(1):51-60

https://aeji.journals.ekb.eg/

http://mis.zu.edu.eg/ajied/home.aspx 
were entered in multivariable binary logistic regression analysis to identify independent predictors of CRS. If two predictors showed high collinearity, we chose one of them based on more logical association with CRS. We used the backward method to build the predictive model.

Two-tailed P-values $<0.05$ are considered statistically significant.

\section{RESULTS}

In our study evaluating 160 COVID 19 ICU patients the acute cardiac injury was reported in 36 patients out of 160 (22.5\%), whereas AKI was reported in 18 patients (11.25\%), whilst CRS developed in 8 patients representing $5 \%$.

Bi-variable logistic regression analysis investigated the following parameters in relation to occurrence of cardio-renal syndrome (CRS):

Regarding the demographic data: Hypertension, sex, DM, IHD, COPD, AF, CKD, Morbid obesity or cancer; there were no significant statistical differences in relation to CRS occurrence, $(\mathrm{P}>0.05)$ but as regards age there was a significant statistical difference with $(\mathrm{P}=0.0004)$

Concerning the labs for predicting CRS types 1, 3 and 5 [9]: Total leucocytic count, lymphocytic count, hemoglobin level, C-Reactive Protein, albuminuria, ALT, LDH, total CPK, or cardiac markers (CK-MB, Troponin I), there were no significant statistical differences in association with CRS occurrence with $(\mathrm{P}>0.05)$ but serum creatinine and serum $\mathrm{K}$ were statistically significant at $(\mathrm{P}=0.015,0.021)$ respectively whereas GFR and D-dimer were found to be highly statistically significant with (p 0.0001, $0.001)$ respectively

As regards Radiological evaluation; nephropathy by pelvi-abdominal ultrasound, Echo (Ejection Fraction (EF), resting segmental wall motion abnormality (RSWMA) and Right Ventricular Systolic Pressure (RVSP)) and CT chest Findings (Ground glass opacity (GGO), crazy paving and bilateral lung affection) there were no significant statistical differences with $(\mathrm{P}>0.05)$

With regards to the need for mechanical ventilation and vasopressors there were high statistical significances with $(\mathrm{P}<0.001,0.00004)$ respectively.

Multivariable logistic regression analysis showed that only the following parameters were independent predictors for CRS; eGFR (odds ratio $0.911,95 \% \mathrm{CI}=0.861$ to $0.964, \mathrm{P}$-value $=$ 0.008 ) and serum potassium on admission (odds ratio $=0.085,95 \% \mathrm{CI}=0.015$ to $479, \mathrm{P}$-value $=$ 0.005 ) (Table 2).

The regression model had good overall fit ( -2 Log Likelihood Test P-value < 0.0001, Nagelkerke R2 = 0.590). The receiver-operating characteristic (ROC) curve derived from the regression model showed excellent predictive value with an area under the receiver-operating characteristic (ROC) curve (AUC) of 0.951 (SE $=0.032,95 \% \mathrm{CI}=0.905$ to $0.979, \mathrm{P}$-value < 0.0001). The best cutoff was a predicted probability $>0.010$ (sensitivity $=100 \%$, specificity $=80.3 \%, \mathrm{~J}$-index $=0.803)$. The Correct classification rate for a cutoff probability $>0.5$ was $97.5 \%$. 
Table (1): Comparison of COVID-19 patients who developed cardio-renal syndrome (CRS) and those who did not.

\begin{tabular}{|c|c|c|c|c|}
\hline Variable & All patients $(n=160)$ & No CRS $(n=152)$ & $C R S(n=8)$ & P-value* \\
\hline Age (years) & $58.5(51.0$ to 67.0$)$ & $57.5(48.5$ to 66.0$)$ & $74.5(67.5$ to 79.5$)$ & 0.0004 \\
\hline Male sex & $98(61.3 \%)$ & $92(60.5 \%)$ & $6(75.0 \%)$ & 0.486 \\
\hline Hypertension & $84(52.5 \%)$ & $78(51.3 \%)$ & $6(75.0 \%)$ & 0.282 \\
\hline $\mathrm{DM}$ & $58(36.3 \%)$ & $56(36.8 \%)$ & $2(25.0 \%)$ & 0.712 \\
\hline IHD & $22(13.8 \%)$ & $20(13.2 \%)$ & $2(25.0 \%)$ & 0.303 \\
\hline COPD & $16(10.0 \%)$ & $14(9.2 \%)$ & $2(5.0 \%)$ & 0.184 \\
\hline $\mathrm{AF}$ & $18(11.3 \%)$ & $18(11.8 \%)$ & $0(0.0 \%)$ & 0.599 \\
\hline CKD & $42(26.3 \%)$ & $38(25.0 \%)$ & $4(50.0 \%)$ & 0.208 \\
\hline Morbid obesity & $2(1.3 \%)$ & $2(1.3 \%)$ & $0(0.0 \%)$ & 1.000 \\
\hline Cancer & $2(1.3 \%)$ & $2(1.3 \%)$ & $0(0.0 \%)$ & 1.000 \\
\hline Hemoglobin (g/dl) & $12(10.4$ to 13.0$)$ & $12(10.4$ to 13.0$)$ & $12.2(9.6$ to 12.8$)$ & 0.695 \\
\hline $\operatorname{TLC}\left(\mathrm{k} / \mathrm{mm}^{3}\right)$ & $7.6(5.7$ to 9.1$)$ & $7.5(5.7$ to 9.0$)$ & $12.6(7.6$ to 14.8$)$ & 0.058 \\
\hline Lymphocytes $\left(\mathrm{k} / \mathrm{mm}^{3}\right)$ & $0.9(0.6$ to 1.2$)$ & $0.9(0.6$ to 1.2$)$ & $1.05(0.7$ to 1.5$)$ & 0.371 \\
\hline Platelets $\left(\mathrm{k} / \mathrm{mm}^{3}\right)$ & $248(200.5$ to 339.5$)$ & 248 (202.0 to 339.5) & $235(150.0$ to 357.5$)$ & 0.434 \\
\hline CRP (mg/l) & 73 (39.0 to 146.0$)$ & 72.5 (36.5 to 148.5$)$ & $92(65.5$ to 109.5$)$ & 0.950 \\
\hline Creatinine (mg/dl) & $1.05(0.9$ to 1.3$)$ & $1.0(0.9$ to 1.3$)$ & $1.9(1.4$ to 2.1$)$ & 0.015 \\
\hline eGFR (ml/min) & $70.5(50.1$ to 89.0$)$ & $74.3(55.7$ to 90.2$)$ & $33.4(28.5$ to 35.5$)$ & 0.0001 \\
\hline Albuminuria & $22(13.8 \%)$ & $22(14.5 \%)$ & $0(0.0 \%)$ & 0.600 \\
\hline $\begin{array}{l}\text { Nephropathy grade I or more by } \\
\text { PAUS }\end{array}$ & $6(3.8 \%)$ & $6(3.9 \%)$ & $0(0.0 \%)$ & 1.000 \\
\hline Serum $\mathrm{K}^{+}(\mathrm{mmol} / \mathrm{l})$ & $4.0(3.7$ to 4.6$)$ & $4.0(3.7$ to 4.6$)$ & $3.3(2.9$ to 4.3$)$ & 0.021 \\
\hline Hypokalemia & $14(8.8 \%)$ & $10(6.6 \%)$ & $4(50.0 \%)$ & 0.002 \\
\hline Serum ferritin $(\mathrm{ng} / \mathrm{ml})$ & 860.5 (566.5 to 1300.0$)$ & $877(575.0$ to 1300.0$)$ & $959.0(825.5$ to 1374.5$)$ & 0.324 \\
\hline D-Dimer (ng/ml) & $959(721.5$ to 2241.5$)$ & 915.5 (706.0 2052.5) & $\begin{array}{l}3162.5(2606.0 \text { to } \\
5517.0)\end{array}$ & 0.001 \\
\hline CK-MB (ng/ml) & $16(12.0$ to 24.5$)$ & $16(12.0$ to 23.5$)$ & 22.5 (15.5 to 28.0$)$ & 0.178 \\
\hline CK $(\mathrm{ng} / \mathrm{ml})$ & $66(34.0$ to 169.5$)$ & $68(32.5$ to 169.5$)$ & $54(48.0$ to 141.0$)$ & 0.938 \\
\hline Troponin (ng/ml) & $19.8(8.5$ to 35.0$)$ & $19.3(8.0$ to 33.8$)$ & $27.5(19.0$ to 417.5$)$ & 0.072 \\
\hline ALT (IU/l) & $35(18.5$ to 52.0$)$ & $37.5(19.0$ to 54.0$)$ & $46.0(41.5$ to 57.0$)$ & 0.163 \\
\hline LDH (IU/l) & $344(261.6$ to 486.5$)$ & $352(262.0$ to 521.7$)$ & $270.6(249.1$ to 318.5$)$ & 0.065 \\
\hline RVSP (mmHg) & $27(24.0$ to 36.5$)$ & $27.5(24.5$ to 36.5$)$ & $24(21.5$ to 35.0$)$ & 0.177 \\
\hline $\mathrm{EF}(\%)$ & $60(55.0$ to 61.5$)$ & $60(55.0$ to 62.0$)$ & $57.5(53.0$ to 60.0$)$ & 0.242 \\
\hline RSWMA & $34(21.3 \%)$ & $30(19.7 \%)$ & $4(50.0 \%)$ & 0.063 \\
\hline Crazy paving on chest CT & $112(70.0 \%)$ & $104(68.4 \%)$ & $8(100.0 \%)$ & 0.107 \\
\hline Bilateral lung affection by CT & $156(97.5 \%)$ & $148(97.4 \%)$ & $8(100.0 \%)$ & 1.000 \\
\hline GGO on chest CT & $156(97.5 \%)$ & $148(97.4 \%)$ & $8(100.0 \%)$ & 1.000 \\
\hline Need for mechanical ventilation & $68(42.5 \%)$ & $60(39.5 \%)$ & $8(100.0 \%)$ & 0.001 \\
\hline Duration of MV (days) & $0(0.0$ to 5.0$)$ & $0(0.0$ to 4.5$)$ & $5(3.5$ to 6.5$)$ & 0.003 \\
\hline Need for vasopressor & $48(30.0 \%)$ & $40(26.3 \%)$ & $8(100.0 \%)$ & 0.00004 \\
\hline Actemra use & $66(41.3 \%)$ & $60(39.5 \%)$ & $6(75.0 \%)$ & 0.066 \\
\hline Mortality & $42(26.3 \%)$ & $6(75.0 \%)$ & $36(23.7 \%)$ & 0.004 \\
\hline
\end{tabular}

Data are presented as median (interquartile range) or number (percentage). *. Quantitative variables are compared using the Mann-Whitney U-test and categorical variables using Fisher's exact test. Data are presented as median (interquartile range) or number (percentage). *. Quantitative variables are compared using the MannWhitney U-test and categorical variables using Fisher's exact test.

Table (2): Backward multivariable binary logistic regression analysis for prediction of cardio-renal syndrome (CRS) in COVID-19 patients

\begin{tabular}{|l|c|c|c|c|c|c|}
\hline Variable* $^{*}$ & $B$ & $S E$ & Wald & P-value & Odds ratio & $95 \%$ CI \\
\hline Age (years) & 0.086 & 0.047 & 3.444 & 0.064 & 1.090 & 0.995 to 1.195 \\
\hline eGFR on admission $(\mathrm{ml} / \mathrm{min})$ & -0.079 & 0.030 & 6.994 & 0.008 & 0.924 & 0.871 to 0.980 \\
\hline Serum $\mathrm{K}^{+}$on admission $(\mathrm{mmol} / \mathrm{l})$ & -2.470 & 0.885 & 7.790 & 0.005 & 0.085 & 0.015 to 0.479 \\
\hline Constant & 4.735 & 4.642 & 1.040 & 0.308 & & \\
\hline
\end{tabular}

$\mathrm{B}=$ regression coefficient, $\mathrm{SE}=$ standard error, Wald $=$ Wald chi-squared statistic, $95 \% \mathrm{CI}=95 \%$ confidence interval. 
*Removed variables by backward regression: D-dimer at admission, need for mechanical ventilation and need for vasopressors.

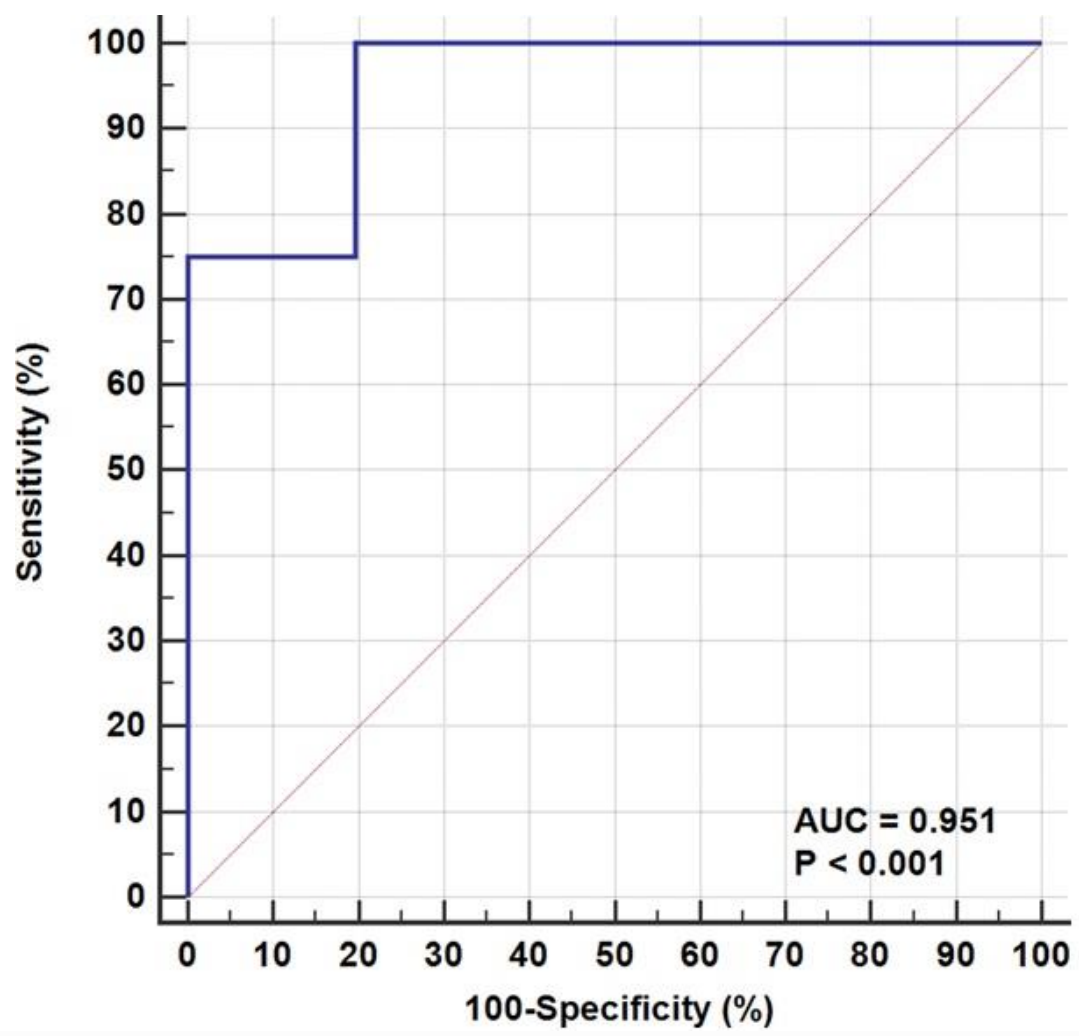

Figure 1. Receiver-operating characteristic (ROC) curve derived from backward multivariable binary logistic regression analysis for prediction of cardio-renal syndrome (CRS) in COVID-19 patients. Area under the ROC curve $(\mathrm{AUC})=0.951(\mathrm{SE}=0.032,95 \% \mathrm{CI}=0.905$ to $0.979, \mathrm{P}$-value $<0.0001)$. Best cutoff is predicted probability $>0.01$ (Sensitivity $=100 \%$, specificity $=80.3 \%$, J-index $=0.803)$. Correct classification rate for cutoff probability $>0.5=97.5 \%$. 


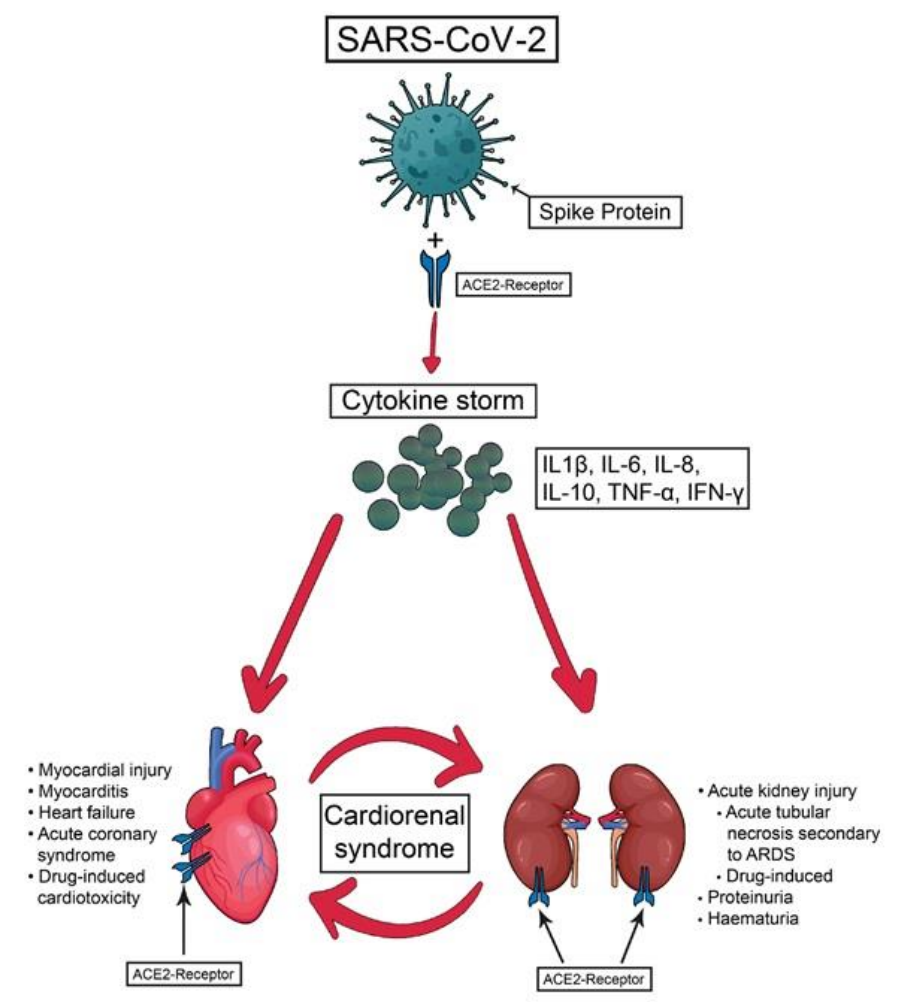

Figure 2: Explanation of Cardio-renal Syndrome in Covid 19

\section{DISCUSSION}

Since the last December, the entire world is experiencing a new pandemic situation, the severe acute respiratory syndrome coronavirus 2 (SARS-CoV-2). Owing to all of its mysterious factors, physicians are passing via real-time learning process. Though COVID-19 clinical manifestations are primarily respiratory, however major cardiac and renal complications have been documented in a significant number of patients with COVID-19 [10-12].

\section{Cardiac injury in covid-19 patients:}

Our study displayed that acute cardiac injury occurred in 36 patients out of 160 denoting $22.5 \%$. Whereas acute cardiac injury was conveyed in $25.3 \%$ (95\% CI $19.5-31.1 \%$ ) of covid-19 patients, which came in parallel to our results [13-17].

It is speculated that cardiac injury might result from one or more of the presumed mechanisms: direct invasion by the virus, indirect damage due to the systemic inflammatory syndrome and cytokine storm, dysregulation of reninangiotensin-aldosterone system, hypoxia-induced cardiac injury, microvasculature damage of the heart, stress-induced cardiomyopathy, and cardiac damage secondary to multi-organ failure [18-20].

A varied range of cardiovascular disease has been described in patients with COVID-19 which encompasses acute myocarditis (including acute lymphocytic myocarditis) [21], fulminant myocarditis [22-24], acute myocardial infarction type 2 [25], acute myopericarditis [26], acute pulmonary embolism [27-30], cardiac tamponade [26], cardiogenic shock $[31,32]$, cardiomyopathy [33], heart failure, pericardial effusion, pulmonary hypertension,

\section{AKI in covid-19 patients:}

In our study, the detection rate of AKI in COVID-19 patients was $11.25 \%$, which came in line with many reports of [1], [4], [9], [14]; However other studies showed the prevalence of AKI specified in $8.8 \%$ of studies (95\% CI 5.412.2\%) [15-17].

The mechanisms involved in the pathology of AKI in COVID-19 patients are supposed to be multifactorial. The exceptional COVID 19 infection might imply direct cytopathic effects on kidney tissue. On the other side, deposition of immune complexes of viral antigen or virusinduced specific immunological effector 
mechanisms might apply. Lastly, virus-induced cytokines or mediators will produce injurious effects on renal tissue, such as hypoxia, shock, and rhabdomyolysis [41].

ACE2 is expressed in the heart and kidney, which might provide a link between COVID infection and the cardio-renal system. When COVID infection evolves, downregulation of ACE2 leads to increased angiotensin II action with loss of the cardioprotective effects $[\mathbf{3 , 3 5}$ 39].

Nevertheless, consistent with the cardiovascular consequences of a renin-angiotensin systemdamaging infection, there is a growing data about the significant contribution from extrapulmonary cardio-renal manifestations, including arrhythmias, acute cardiac injury and acute kidney injury; hence this could be regarded as a Type 5 (secondary) CRS (see Figure 2) [40].

The Pathogenesis pathways for cardio-renal syndrome were concomitant with SARS-CoV-2 infection.

There are various types for the eminent cardiorenal syndrome whereas in COVID 19 the most allied one is type 5 followed by type I and 3.It happens when a devastating injury causes a concomitant development of AKI and acute cardiac injury [39].

Many studies were done evaluating the predictors of CRS development before the era of covid-19 virus pandemic. However, it is not yet known whether these data can be conducted similarly on covid-19 patients or not. Likewise, data is scarce in this aspect and further studies on this issue should be conducted.

Our study is the only current one investigating the relation of cardio-renal syndrome and poor outcome in patients with COVID- 19.

Regarding the demographic data in the present study, the older age which proved to be a strong predictor for cardio-renal injury after exclusion of the confounding factors. This finding can be attributed to the fact that ACE2 roles as a receptor for the entry of SARS-CoV-2 into the cell, so the presence of age as a strong predictor for CRS in covid-19 patients may be partly concealed in the age-related differences in the renin-angiotensin-aldosterone system (RAAS). Moreover, this rationale is based on the finding that the elderly are more susceptible to severe forms of COVID-19 [34].
Étard JF et al supported the finding that the elderly are more predisposed to severe forms of COVID-19 [40-42]. Furthermore, Musso et al. reported that advancing age adversely affects the RAAS $[43,44]$ which came in line with Luwen et al results as all mortalities were over 60 years [45].

As regards laboratory values, $\mathrm{Hb}$ level, total leucocytic count, lymphocytic count, CRP, ferritin, albuminuria, or cardiac markers (Total CPK, CK-MB, Troponin I), LDH, ALT, there was no significant statistical difference between both groups with $(\mathrm{P}>0.05)$. On the other hand, serum $\mathrm{K}+$, serum creatinine were significant with $P$ values 0.021 and 0.015 respectively and eGFR and D-dimer were highly significant with $\mathrm{P}$ values $<0.001$.The relation of GFR on admission with CRS occurrence in covid-19 patients might be explained by the hypothesis that the low GFR values could drive the renal tubules more vulnerable to damage by cytokine storm leading to acute kidney injury with subsequent cardiac derangement resulting in the so called cardiorenal syndrome [46].

In a study that was done by Yao $\mathrm{Y}$ et al to evaluate D-dimer as a biomarker for covid-19 severity showed that D-dimer levels correlated significantly with the disease severity and was associated with a significant rise in troponin and serum creatinine that may explain our results as regards correlation between CRS and serum Ddimer [47].

In our study all the patients who developed CRS had specific CT findings for Covid-19 patients ; as crazy paving and bilateral peripheral lung affection and GGO on CT Chest .However there was no significant correlation between the CT chest outcomes and CRS occurrence which may be attributed to the fact that most of the patients enrolled in our study had CT findings (156 out of 160) which represented $97.5 \%$ denoting the severity of the pulmonary manifestations of the patients enrolled in our study.

Discordantly the study done by Zhang $\mathrm{J}$ et al conveyed that CT score was a valuable tool for the severity of systemic inflammation [48]

The need for mechanical ventilation and vasopressors showed a high statistical significant correlation with covid patients developed CRS P value $<0.001$ and $<0.00004$ respectively.

Although we found strong association between the need for Mechanical ventilation or 
vasopressor and incidence of cardio-renal syndrome, this relation could not be shown on multivariable analysis. This could be explained by the relatively small sample size and low statistical power of the sample or low occurrence of cardio-renal syndrome 5\% as concordant with previously reported studies.

All the patients enrolled in our study were critically ill who needed ICU admission with a large proportion of them who needed mechanical ventilation and vasopressors. As expected the severity of their illness might be related to the severity of the COVID 19 infection and this may be attributed to the cytokine storm with a rapid deleterious effect concomitantly to both the kidney and heart.

Also on multivariable regression analysis unexpectedly hypokalemia showed a strong association as a predictor of cardio-renal syndrome ( $\mathrm{P}$ value 0.005). Hypokalemia is associated with increased risk of arrhythmia like; ventricular tachycardia/fibrillation, bradycardia by prolonging the QT interval, as well as increased all-cause mortality, cardiovascular mortality and heart failure mortality by up to 10 fold. Additively there are deleterious sequelae for hypokalemia on kidney leading to hypokalemic nephropathy, rhabdomyolysis [49,50].

However, hypokalemia may be induced by factors such as anorexia, medication induced diarrhea, viral injury to the gut, and the use of diuretics and corticosteroids.

Low potassium levels found in urine samples from patients with severe COVID-19 may possibly cause acute kidney injury, causing abnormal potassium handling. Another explanation is that the rennin-angiotensin system is abnormally activated by the loss of ACE2 function in disrupted cells.

This is a unique study showing an association between cardio-renal concomitant morbidity and poor outcome in patients with COVID-19. Besides, CRS was associated with higher mortality $(75.0 \%$ versus $27.3 \%$ with non-CRS, P-value $=0.004)$, with an unadjusted odds ratio of $9.67(95 \% \mathrm{CI}=1.87$ to 50.01 , P-value $=$ 0.007 )

This is not different from reported mortality of CRS in non covid patients, and this may be explained by severe cytokine storm that caused simultaneous damage to heart and kidney with ensuing cardiogenic shock, renal, myocardial hypoperfusion and then multi-organ failure. This inflammatory response reflected a picture close to cardio-renal syndrome type 5 resulting from sepsis, which is the worst prognosis according to the literature [51]

\section{CONCLUSION}

Cardio-renal syndrome was not uncommon in COVID-19 ICU patients. Hypokalemia, lower GFR on admission, mechanical ventilation, vasopressors, age and D-dimer were significant independent predictors for CRS. Moreover,CRS during hospitalization was associated with an increased risk of in-hospital death.

Limitations: A relatively small sample size and unicentered study which caused a low statistical power for it. This might have hindered the translation for most of our CRS predictors to be independent ones after the exclusion of the confounding factors.

Recommendations: Larger scale and multicenter studies are needed to define the clinical spectrum and mechanisms of the newly developed cardio-renal syndrome in covid-19 patients and to investigate thoroughly the predictors and ideal ways for prevention and their proper management.

Acknowledgement: No contributions from any external body have been made to the production of this article.

Statement of Ethics: The paper is exempt from ethical committee approval as all the expenses of the procedures done have all been covered by the authors.

Conflict of Interest Statement: There is no conflict of interest between the authors.

Funding Sources: No external sources were involved in the funding of this study.

Author Contributions: Dr Aber Halim Baki and Dr Hazem Mansour have contributed to the Review and literature of the paper, Dr Ahmed Tarek El Khouly and Dr Osama Farrag have contributed to the data collection required for this article to be made. 


\section{REFERENCES}

1. World Health Organization, Coronavirus disease (COVID-19) Situation Report - 115, Data as received by WHO from national authorities by 10:00 CEST, 14 May 2020. Vol 2020.

2. Lai CC, Liu YH, Wang CY, Wang YH, Hsueh SC, Yen MY, Ko WC, Hsueh PR. Asymptomatic carrier state, acute respiratory disease, and pneumonia due to severe acute respiratory syndrome coronavirus 2 (SARS-CoV-2): Facts and myths. J Microbiol Immunol Infect. 2020 Jun;53(3):404-412.

3. Arentz M, Yim E, Klaff L, Lokhandwala S, Riedo FX, Chong M, Lee M. Characteristics and Outcomes of 21 Critically Ill Patients With COVID-19 in Washington State. JAMA. 2020 Apr 28;323(16):1612-1614.

4. Wan S, Xiang Y, Fang W, Zheng Y, Li B, Hu Y, et al.Clinical features and treatment of COVID-19 patients in northeast Chongqing. J Med Virol. $2020 \mathrm{Jul} ; 92(7): 797-806$.

5. Zheng Y-Y, Ma Y-T, Zhang J-Y, Xie X. COVID19 and the cardiovascular system. Nature Reviews Cardiology 2020; 17:259-260

6. Li JW, Han TW, Woodward M, Anderson CS, Zhou H, Chen YD, Neal B. The impact of 2019 novel coronavirus on heart injury: A Systematic review and Meta-analysis. Prog Cardiovasc Dis. 2020 Jul-Aug;63(4):518-524.

7. Kidney International Supplements (2012) 2, 1; doi:10.1038/kisup.2012.1

8. Naing L, Winn T, Rusli BN. Practical issues in calculating the sample size for prevalence studies. Archives of Orofacial Sciences 2006; 1: 9-14.

9. Nickson C. Cardiorenal syndrome - LITFL • CCC Cardiology. Retrieved August 22, 2020, from https://litfl.com/cardiorenal-syndrome. 2019

10. Shi S, Qin M, Shen B, Cai Y, Liu T, Yang F et al. Association of Cardiac Injury With Mortality in Hospitalized Patients With COVID-19 in Wuhan, China. JAMA Cardiol. 2020 Jul 1;5(7):802-810.

11. Wang D, Hu B, Hu C, Zhu F, Liu X, Zhang J,et al. Clinical Characteristics of 138 Hospitalized Patients With 2019 Novel Coronavirus-Infected Pneumonia in Wuhan, China. JAMA. 2020 Mar 17;323(11):1061-1069.

12. $\mathrm{Hu} \mathrm{H}$, Ma F, Wei X, Fang Y. Coronavirus fulminant myocarditis saved with glucocorticoid and human immunoglobulin. Eur Heart J. 2020 Mar 16:ehaa190.

13. Xanthopoulos A, Starling RC, Kitai T, Triposkiadis F. Heart failure and liver disease: cardiohepatic interactions. JACC Heart Fail 2019; 7:87-97.

14. Samsky MD, Patel CB, DeWald TA, Smith AD, Felker GM, Rogers JG, Hernandez AF. Cardiohepatic interactions in heart failure: an overview and clinical implications. J Am Coll Cardiol. 2013 Jun 18;61(24):2397-2405.
15. Tabucanon T, Tang WHW. Right Heart Failure and Cardiorenal Syndrome. Cardiol Clin 2020; 38:185-202.

16. Raina R, Nair N, Chakraborty R, Nemer L, Dasgupta R, Varian K. An Update on the pathophysiology and treatment of cardiorenal syndrome. Cardiol Res 2020; 11:76-88.

17. Savira F, Magaye R, Liew D, Reid C, Kelly DJ, Kompa AR,et al. Cardiorenal syndrome: Multiorgan dysfunction involving the heart, kidney and vasculature. $\mathrm{Br} \quad \mathrm{J}$ Pharmacol. 2020 Jul;177(13):2906-2922.

18. Han H, Xie L, Liu R, Yang J, Liu F, Wu K, et al. Analysis of heart injury laboratory parameters in 273 COVID-19 patients in one hospital in Wuhan, China. J Med Virol. 2020 Jul;92(7):819-823.

19. Libby P. The Heart in COVID-19: Primary Target or Secondary Bystander? JACC Basic Transl Sci. 2020 Apr 10;5(5):537-542.

20. Tan W, Aboulhosn J. The cardiovascular burden of coronavirus disease 2019 (COVID-19) with a focus on congenital heart disease. Int J Cardiol. 2020 Jun 15;309:70-77.

21. Sala S, Peretto G, Gramegna M, Palmisano A, Villatore A, Vignale D, et al.Acute myocarditis presenting as a reverse Tako-Tsubo syndrome in a patient with SARS-CoV-2 respiratory infection. Eur Heart J. 2020 May 14;41(19):1861-1862.

22. Irabien-Ortiz Á, Carreras-Mora J, Sionis A, Pàmies J, Montiel J, Tauron M. Fulminant myocarditis due to COVID-19. Rev Esp Cardiol (Engl Ed). 2020 Jun;73(6):503-504.

23. Hu H, Ma F, Wei X, Fang Y. Coronavirus fulminant myocarditis saved with glucocorticoid and human immunoglobulin. Eur Heart J. 2020 Mar 16:ehaa190.

24. Zeng JH, Liu YX, Yuan J, Wang FX, Wu WB, Li JX, et al. First case of COVID-19 complicated with fulminant myocarditis: a case report and insights. Infection. 2020 Oct;48(5):773-777.

25. Fox SE, Akmatbekov A, Harbert JL, Li G, Quincy Brown J, Vander Heide RS. Pulmonary and cardiac pathology in African American patients with COVID-19: an autopsy series from New Orleans. Lancet Respir Med. 2020 Jul;8(7):681686.

26. Zheng F, Tang W, Li H, Huang YX, Xie YL, Zhou ZG. Clinical characteristics of 161 cases of corona virus disease 2019 (COVID-19) in Changsha. Eur Rev Med Pharmacol Sci 2020; 24:3404-3410.

27. Leonard-Lorant I, Delabranche X, Severac F, et al. Acute pulmonary embolism in COVID-19 patients on CT angiography and relationship to D-dimer levels. Radiology. 2020:201561.

28. Casey K, Iteen A, Nicolini R, Auten J. COVID-19 pneumonia with hemoptysis: Acute segmental pulmonary emboli associated with novel coronavirus infection. Am J Emerg Med. 2020 Jul;38(7):1544.e1-1544.e3. 
29. Fabre O, Rebet O, Carjaliu I, Radutoiu M, Gautier L, Hysi I. Severe Acute Proximal Pulmonary Embolism and COVID-19: A Word of Caution. Ann Thorac Surg. 2020 Nov;110(5):e409-e411.

30. Cellina M, Oliva G. Acute pulmonary embolism in a patient with COVID-19 pneumonia. Diagn Interv Imaging. 2020 May;101(5):325-326.

31. Tavazzi G, Pellegrini C, Maurelli M, Belliato M, Sciutti F, Bottazzi A,et al. Myocardial localization of coronavirus in COVID-19 cardiogenic shock. Eur J Heart Fail. 2020 May;22(5):911-915.

32. Fried JA, Ramasubbu K, Bhatt R, Topkara VK, Clerkin KJ, Horn E,et al. The Variety of Cardiovascular Presentations of COVID-19. Circulation. 2020 Jun 9;141(23):1930-1936.

33. Juusela A, Nazir M, Gimovsky M. Two cases of coronavirus 2019-related cardiomyopathy in pregnancy. Am J Obstet Gynecol MFM. 2020 May;2(2):100113.

34. Sala S, Peretto G, Gramegna M, Palmisano A, Villatore A, Vignale D,et al. Acute myocarditis presenting as a reverse Tako-Tsubo syndrome in a patient with SARS-CoV-2 respiratory infection. Eur Heart J. 2020 May 14;41(19):1861-1862.

35. Ronco C, Haapio M, House AA, Anavekar N, Bellomo R. Cardiorenal syndrome. J Am Coll Cardiol. 2008 Nov 4;52(19):1527-39.

36. Sun ML, Yang JM, Sun YP, Su GH. [Inhibitors of RAS Might Be a Good Choice for the Therapy of COVID-19 Pneumonia]. Zhonghua Jie He He Hu Xi Za Zhi. 2020 Mar 12;43(3):219-222. Chinese.

37. Driggin E, Madhavan MV, Bikdeli B, Chuich T, Laracy J, Biondi-Zoccai G,et al.Cardiovascular Considerations for Patients, Health Care Workers, and Health Systems During the COVID-19 Pandemic. J Am Coll Cardiol. 2020 May 12;75(18):2352-2371.

38. Tam CF, Cheung KS, Lam S, Wong A, Yung A, Sze M,et al. Impact of Coronavirus Disease 2019 (COVID-19) Outbreak on ST-Segment-Elevation Myocardial Infarction Care in Hong Kong, China. Circ Cardiovasc Qual Outcomes. 2020 Apr;13(4):e006631.

39. Zhou F, Yu T, Du R, Fan G, Liu Y, Liu Z, et al. Clinical course and risk factors for mortality of adult inpatients with COVID-19 in Wuhan, China: a retrospective cohort study. Lancet. 2020 Mar 28;395(10229):1054-1062.

40. Apetrii M, Enache S, Siriopol D, Burlacu A, Kanbay A, Kanbay M,et al. A brand-new cardiorenal syndrome in the COVID-19 setting. Clin Kidney J. 2020 Jun 4;13(3):291-296.
41. Liu K, Chen Y, Lin R, Han K. Clinical features of COVID-19 in elderly patients: A comparison with young and middle-aged patients. J Infect. 2020 Jun;80(6):e14-e18.

42. Etard JF, Vanhems P, Atlani-Duault L, Ecochard R. Potential lethal outbreak of coronavirus disease (COVID-19) among the elderly in retirement homes and long-term facilities, France, March 2020. Euro Surveill. 2020 Apr;25(15):2000448.

43. Andersen K. Renin-angiotensin-aldosterone system in the elderly: rational use of aliskiren in managing hypertension. Clin Interv Aging. 2009; 4:137-151.

44. Musso CG, Jauregui JR. Renin-angiotensinaldosterone system and the aging kidney. Exp Rev Endocrinol Metabol. 2014;9:543-546.

45. Wang L, Li X, Chen H, Yan S, Li D, Li Y, Gong Z. Coronavirus Disease 19 Infection Does Not Result in Acute Kidney Injury: An Analysis of 116 Hospitalized Patients from Wuhan, China. Am J Nephrol. 2020;51(5):343-348.

46. Uribarri A, Núñez-Gil IJ, Aparisi A, BecerraMuñoz VM, Feltes G, Trabattoni D,et al; HOPE COVID-19 Investigators. Impact of renal function on admission in COVID-19 patients: an analysis of the international HOPE COVID-19 (Health Outcome Predictive Evaluation for COVID 19) Registry. J Nephrol. 2020 Aug;33(4):737-745.

47. Yao Y, Cao J, Wang Q, Shi Q, Liu K, Luo Z,et al. D-dimer as a biomarker for disease severity and mortality in COVID-19 patients: a case control study. J Intensive Care. 2020 Jul 10;8:49.

48. Zhang J, Meng G, Li W, Shi B, Dong H, Su Z, et al. Relationship of chest CT score with clinical characteristics of 108 patients hospitalized with COVID-19 in Wuhan, China. Respir Res. $2020 \mathrm{Jul}$ 14;21(1):180.

49. Hypokalemia and sudden cardiac death. Kjeldsen $K$ Experimental and Clinical Cardiology 2010; 15(4):e96-9

50. Alfano G, Ferrari A, Fontana F, Perrone R, Mori G, Ascione E, Magistroni R,et al.; Modena Covid19 Working Group (MoCo19). Hypokalemia in Patients with COVID-19. Clin Exp Nephrol. 2021 Jan 4:1-9.

51. Mavrakanas TA, Khattak A, Singh K, Charytan DM. Epidemiology and Natural History of the Cardiorenal Syndromes in a Cohort with Echocardiography. Clin J Am Soc Nephrol. 2017 Oct 6;12(10):1624-1633 